\title{
Wilms' tumour and a de novo $(1 ; 7)$ translocation in a child with bilateral radial aplasia
}

\author{
M Hewitt, P W Lunt, A Oakhill
}

\begin{abstract}
The case of a child with nephroblastoma, bilateral radial aplasia, and a de novo $(1 ; 7)$ translocation is reported.
\end{abstract}

The association between abnormal karyotypes, dysmorphic syndromes, and childhood malignancy is well known. ${ }^{1}$ We report the presence of a nephroblastoma in a boy with bilateral radial aplasia and a balanced de novo $(1 ; 7)$ translocation.

\section{Case report}

The patient was the first child of healthy, unrelated parents who both came from the same small village in southern Italy. He was born at 37 weeks after a clomiphene induced pregnancy and had a birth weight of $3280 \mathrm{~g}$ (>10th centile).

Bilateral radial aplasia was noted clinically after birth, as was shortening of the lower limbs. All digits were present, he had a normal facies, and there was no clinical evidence of cardiac anomalies. Full blood count at this time showed a haemoglobin of $17 \cdot 1 \mathrm{~g} / \mathrm{dl}$, total white cell count $14 \cdot 2 \times 10^{9} / 1$, and the platelets were low at $78 \times 10^{9} / 1$. There were no clinical problems from the thrombocytopenia and the count returned to normal values on the fourth day.

Radiological investigation confirmed the radial aplasia and also showed other skeletal anomalies. On the right hand there was absence of the first metacarpal and proximal phalanx of the thumb and

Royal Hospital for Sick Children, St Michael's Hill, Bristol BS2 8BJ.

M Hewitt, P W Lunt, A Oakhill

Correspondence to Dr Hewitt.

Received for publication 4 September 1990.

Revised version accepted for publication 12 November 1990. hypoplasia of the distal phalanx. The left hand had a hypoplastic first metacarpal and proximal phalanx of the thumb. Hypoplasia of the middle phalanx of the left fifth finger was also seen. Shortening of both tibiae and fibulae was present.

At 5 years of age a large, left sided abdominal mass was found. Radiological investigations suggested an intrarenal mass on the left with splaying of the lower pole calyces. At laparotomy, however, a white lesion was noted on the anterior surface of the right kidney and consequently surgery was limited to bilateral renal biopsies. Histology showed small round cells consistent with nephroblastoma from the left kidney and blastoma cells from the right kidney. There was no evidence of regional spread. He was therefore assumed to have a stage I (favourable histology) tumour (staging from the United Kingdom National Wilms' Tumour Study). At this presentation his haemoglobin was $12.0 \mathrm{~g} / \mathrm{dl}$, WCC $10.4 \times 10^{9} / 1$, and platelets $344 \times 10^{9} / 1$.

\section{CYTOGENETIC STUDIES}

Chromosome analysis showed a balanced reciprocal translocation between the long arm of chromosome 1 and the short arm of chromosome $7(46, \mathrm{XY}, \mathrm{t}(1 ; 7)$ (q42;p15). Levels of chromosome damage in cultures exposed to alkylating agents were within normal limits. Both parents had normal karyotypes.

\section{Discussion}

Associations between malignancies and other congenital defects may help in the understanding of the underlying genetic abnormalities.

Wilms' tumour is the most common renal tumour in children and its association with deletions of the short arm of chromosome 11 is well recognised. ${ }^{1}$ Skeletal defects in children with Wilms' tumour have been described,,$^{2}$ although most are positional 
deformities. There is a report of a 3 year old girl with 'hypoplasia of radii', 2 although no other details are given. There are no published reports of a Wilms' tumour being associated with a bilateral limb aplasia syndrome.

It is difficult, however, to determine a syndrome which would encompass all the clinical features of this patient. Limb aplasia is a major finding in the thrombocytopenia-absent radii (TAR) syndrome, Fanconi's anaemia, and the Holt-Oram syndrome.

The TAR syndrome is suggested by the low platelet count but this was transient and limited to the immediate postnatal period when other factors may have been responsible. Also, TAR does not usually include abnormalities of the thumb. ${ }^{4}$ In favour of this diagnosis is its recessive inheritance (both parents were from the same geographical area) and the selective hypoplasia of the middle phalanx of the fifth finger (a characteristic finding in 35 of 41 reported cases). ${ }^{4}$

There are no reports of cytogenetic abnormalities associated with TAR syndrome. Fanconi's anaemia was excluded by the presence of normal levels of chromosome damage after exposure to alkylating agents.

The thumb abnormalities would suggest the dominantly inherited Holt-Oram syndrome, but there was no evidence of structural cardiac anomalies which are seen in $85 \%$ of cases. ${ }^{5}$ There were no known cardiac or skeletal anomalies in either parent but a new dominant mutation cannot be excluded.
The location of the gene responsible for the HoltOram syndrome is not known, but there is one case report with abnormalities confined to a B group chromosome $(4 \text { or } 5)^{6}$ and another associated with a $14 \mathrm{q}$ deletion.?

There are no previous reports of radial aplasia or Wilms' tumour associated with chromosomal anomalies involving either region $1 \mathrm{q} 42$ or $7 \mathrm{p} 15$.

In view of the de novo occurrence in this patient of the chromosomal translocation, the skeletal anomalies, and the Wilms' tumour, it may be that genes located at one or other of the breakpoints in this patient are involved in the evolution of either Wilms' tumour or one of the limb aplasia syndromes.

MH is supported by the Cancer and Leukaemia in Childhood (CLIC) Trust.

1 Pizzo PA, Poplack DG. Principles and practice of pediatric oncology. 1st ed. New York: Lippincott, 1989.

2 Prendergrass TW. Congenital anomalies in children with Wilms' tumour. Cancer 1976;37:403-9.

3 Miller RW, Fraumeni JF, Manning MD. Association of Wilms' tumour with aniridia, hemihypertrophy and other congenital malformations. N Engl F Med 1964;270:922-7.

4 Hedberg VA, Lipton JM. Thrombocytopenia with absent radii. Am $\mathcal{f}$ Pediatr Hematol Oncol 1988;10:51-64.

5 Smith AT, Sack GH, Taylor GJ. Holt-Oram syndrome. $\mathcal{F}$ Pediatr 1979;95:538-43.

6 Ryback M, Kozlowski K, Kreczkowska P, Lewandowska J, Wilk E. Holt-Oram syndrome associated with ectromelia and chromosomal aberration. Am $\mathcal{F}$ Dis Child 1971;121:490-5.

7 Turleau C, de Grouchy J, Chavin-Colin F, et al. Two patients with interstitial del(14q), one with features of Holt-Oram syndrome. Exclusion mapping of PI (alpha-1-antitrypsin). Ann Genet (Paris) 1984;27:237-40. 